\title{
Individuo y razón en la teoría crítica de la Escuela de Francfort
}

Es una constante histórica que, en los momentos de crisis, en los momentos en que la humanidad intenta revisar el sentido de su existencia, se encuentre con el individuo.

Esto sucedió en tiempo de los sofistas, de la cultura helenística, de la crisis de la escolástica, del renacimiento y de la llustración, y esto mismo sucede en nuestra sociedad industrial.

La Escuela de Francfort reconoce que el concepto de individuo va unido al de razón: «La desintegración del individuo y de la razón son una y la misma cosa».

En la llustración, punto de partida de la Escuela de Francfort, se había llegado a un individuo despersonalizado, abstracto. El propósito de Horkheimer y Adorno, al igual que el de Marcuse, será potenciar este sujeto libre, capaz de modelar conscientemente la vida social venidera. Para ello ningún apoyo mejor que la razón según se pone de manifiesto en esta frase de Horkheimer: "La decadencia de la razón y la decadencia del individuo son idénticas».

El mismo Adorno considera al individuo aislado amenazado por el sistema monopolista. La conciencia individual ha perdido su carácter en función de la totalidad en cuyo seno los individuos son manipulados.

El tema de la dialéctica de la llustración es uno de los temas fundamentales de la Escuela de Francfort. Ya había sido planteado por Horkheimer en 1932; y en 1937 por Marcuse en «Sobre el carácter afirmativo de la cultura». El punto de partida de las reflexiones lo constituye en primer lugar, el manifiesto desequilibrio entre las posibilidades de la humanidad para organizarse de forma razonable y el nuevo género de barbarie al que se había llegado ${ }^{1}$.

1. Horkheimer, M.-Adorno, Th.W., Dialéctica de la llustración, Sur, Buenos Aires 1970, 7. 
«El aumento de la producción económica, que engendra las condiciones para un mundo más justo procura, por otro lado, el aparato técnico y los grupos sociales que disponen de él, una inmensa superioridad sobre el resto de la población. El individuo se ve reducido a cero frente a las potencias económicas. Tales potencias llevan al mismo tiempo a un nivel hasta ahora sin precedentes el dominio de la sociedad frente a la naturaleza. Mientras el individuo desaparece frente al aparato al que sirve, ese aparato lo provee como nunca lo ha hecho" ${ }^{2}$.

Horkheimer y Adorno pueden hacer un análisis crítico entre racionalidad y realidad social y entre naturaleza y dominio de la naturaleza. La razón que debía ser el fundamento de una sociedad racional, debido a su contradicción, tiende hacia lo contrario, hacia un irracionalismo destructivo.

En la moderna sociedad industrial el aumento más material que social se produce a costa de un mayor control sobre el individuo. La racionalidad, más que de fines, es puramente instrumental. «El hombre intenta dominar la naturaleza, pero para ello ha de imponerse leyes a sí mismo, de esta forma el sujeto de la naturaleza es un esclavo. En lugar de intentar comprender el mundo de la naturaleza sólo es posible si el hombre se vuelve contra él mismo, éste es el caso de Ulises y que Adorno denomina «dialéctica del racionalismo». La naturaleza no es interpretada sino que lo que se pretende es dominarla. Éste es pues el mensaje de la «Dialéctica de la llustración». La crítica, a la que se somete la llustración, tiene por objeto preparar un concepto positivo de ésta que la libere de la petrificación en ciego dominio» ${ }^{3}$.

De esta forma se adecúa la realidad a la razón, pues «la verdad no es sólo la conciencia racional sino también una configuración de la realidad» ${ }^{4}$.

Lo que pretenden, pues, Adorno y Horkheimer, es señalar unas características básicas de la razón que parecen acompañar constantemente al pensamiento racional en el curso de su Historia. Adorno y Horkheimer conciben la historia como desarrollo de la razón hacia una autorrealización, pero sin embargo el análisis de la realidad les lleva a la consideración de elementos irracionales, la razón se vuelve, pues, irracional, éste es el fruto que se ha de pagar al desarrollo industrial.

El esfuerzo que se proponen los miembros de la Escuela de Francfort, es liberar al individuo, a la naturaleza humana de todo intento de mitología de la individualidad. Ésta es una idea central de la teoría crítica: impedir que el individuo quede reducido a la totalidad. La idea de Adorno, de que el individuo ha de conservar su autonomía, es algo que aparece a simple vista en sus escritos.

2. Horkheimer, M.-Adorno, Th.W., Dialéctica de la llustración, 11.

3. Horkheimer, M.-Adorno, Th.W., Dialéctica de la llustración, 12.

4. Horkheimer, M.-Adorno, Th.W., Dialéctica de la llustración, 10. 
La reconciliación entre el sujeto y la realidad objetiva aportada por la filosofía hegeliana es desenmascarada por Adorno, que manifiesta que se trata de la ilusión suprema del idealismo, y esto sólo es posible cuando el sujeto es reducido a puro concepto. Adorno no quiere ir tan lejos como Hegel, la totalidad hegeliana llega a emular todo cuanto es particular.

Para Horkheimer la liberación del individuo, que había sido posible gracias a la economía de mercado, a la libre concurrencia, es por lo tanto inseparable de su represión impuesta por las exigencias de la competencia universal.

La homología entre la muerte histórica del individuo y la de la razón se comprende si tenemos en cuenta que el dominio sobre la naturaleza y la razón se ve reducida, igual que el individuo, a simple medio. La razón, ligada inevitablemente al instinto de conservación, es un instrumento de dominio y de organización» ${ }^{5}$.

En el capítulo de «Crítica de la razón instrumental» que lleva por título «La rebelión de la naturaleza», Horkheimer pretende demostrar cómo el concepto idealista de razón autónoma, típico de la sociedad liberal, se debilita con la aparición del capitalismo monopolista. «La transformación total del mundo, en un mundo más de medios que de fines, es en sí consecuencia del desarrollo histórico de los medios de producción. Al tornarse más complejas y más complicadas la producción material y la organización social, se hace cada vez más difícil reconocer los medios como tales ya que adoptan la apariencia de entidades autónomas» ${ }^{6}$.

Esto es según Horkheimer lo que confiere a la sociedad industrial contemporánea un aspecto nihilista. El hombre se convierte en juguete de la naturaleza rechazada, sacrificada a la disciplina productiva.

Horkheimer en sus estudios sobre el pensamiento burgués, desde Maquiavelo hasta Hegel, esboza la dialéctica entre la razón humana y el dominio sobre la naturaleza nacido del instinto de conservación. Este instinto se deja sentir con una mayor fuerza cuando la revolución burguesa rompe el orden feudal regido por la fe y la razón universales. Para Maquiavelo y Hobbes, la razón es el instrumento de los intereses particulares, del egoísmo individual nacido de las primeras sociedades de mercado. La razón es, para Hobbes, no una facultad infalible, sino como el acto del razonamiento particular de cada hombre. Esta razón es considerada por Horkheimer como razón instrumental, es una razón egoísta nacida de una necesidad del instinto de conservación.

La crítica que hace Hegel al sistema de Hobbes está en función de impli-

5. ZIMA, P.V., La escuela de Frankfort, Galba, Barcelona 1976, 107.

6. Horkheimer, M., Crítica de la razón instrumental, Sur, Buenos Aires 1973, 112. 
car el conocimiento individual en el conocimiento de la totalidad. Sin embargo se quedó en la pura abstracción. La totalidad hegeliana en la que se encuentran reunido sujeto y objeto se ve acusada por la teoría crítica de ser una mistificación de la razón instrumental, que lejos de ser una crítica de la dominación, no es sino una racionalización de ésta. De esta forma el individuo se ve sometido a su propia negación en función del todo. (Tal ocurre en el régimen fascista).

El proceso de la revolución proletaria, a juicio de Horkheimer, parece haber bloqueado la realización histórica de los ideales de la filosofía clásica alemana. Reconociendo que esta identidad de lo particular y lo universal no se encuentra al alcance de la práctica histórica, retrocede a la explicación dualista kantiana que representa la universalidad, no como realidad histórica (Hegel) o como fin histórico (Marx), sino como postulado de la razón práctica. Éste será el fundamento de la universalidad racional, de la razón autónoma incompatible con el interés egoísta que rige la sociedad de mercado. La sociedad no será racional hasta que no se cumpla este deseo kantiano: «lo que será distinto, todavía no es», escribe Adorno. La teoría crítica es negativa en el sentido de liberar al individuo y a la razón del poder establecido del dominio irracional.

De ahí que Horkheimer considere como función social de la filosofía la crítica del orden establecido. "La meta principal de esta crítica es impedir que los hombres se abandonen a aquellos ideales y formas de conducta que la sociedad en su organización actual les dicta. Los hombres deben aprender a discernir la relación entre sus acciones individuales y aquello que se logra con ellas. Entre sus existencias particulares y la vida general de la sociedad ${ }^{7}$.

En su artículo «sobre el concepto de la razón» establece históricamente una doble división del concepto de razón: uno propio de los grandes sistemas filosóficos, donde se concibe a la filosofía como «imagen de la esencia razonable del mundo», en contraposición con éste surge el concepto de razón formal, desvinculado de "toda mezcla con el ser».

Es en este segundo sentido, el concepto de razón se ha hecho instrumental, razonable será lo útil. A este segundo concepto le llama Horkheimer razón subjetiva en cuanto no se ocupa tanto de lo objetivamente razonable, sino que tiene ante la vista lo razonable para el que piensa, para el sujeto, de esta forma los fines quedarán medidos por el que los piensa y no existirá prioridad en ellos, tal es el caso nos dice de Max Weber.

Frente a esta razón que domina únicamente en la conciencia de los individuos surge la conciencia objetiva; esta razón se ha dado nos dice, en Platón,

7. Horkheimer, M., Teoría crítica, Amorrortu, Buenos Aires 1968, 282. 
Aristóteles, la Escolástica y en el idealismo alemán. En ella el criterio de verdad es «la consonancia de una acción con la totalidad».

La razón subjetiva no se enfrentaba a la objetiva, sino que era una expresión limitada de la racionalidad general. «Semejante modo de pensar remitía a la idea de conciliación de un orden objetivo, concebido por la filosofía como razonable, con la existencia humana y su autoconservación» ${ }^{8}$.

En las obras importantes, nos dice Horkheimer, se han actualizado ambos momentos: el subjetivo y el objetivo.

«Si hoy ha de hablarse en un sentido muy radical de una crisis de la razón, ello es, o bien porque el pensamiento es incapaz de captar la idea de lo objetivamente razonable - sin la que la razón subjetiva no pasa tampoco de insegura e inconsciente - o porque el pensamiento comienza a negar aquella idea como una mentira, como un trozo de mitología" ${ }^{9}$. La reducción de la filosofía a la razón subjetiva demuestra que el concepto de razón de la autoconservación comienza a pasar a ser el de autodestrucción.

De esta forma la conciencia subjetiva se convierte en razón instrumental. «El único criterio que reconoce la razón subjetiva, formal, instrumental, es el que el lenguaje del positivismo llama su valor operativo: su papel en la dominación del hombre y la naturaleza» ${ }^{10}$. Todos los conceptos no tendrán más que un significado instrumental, de esta forma el pensamiento mismo instrumentalizado y automatizado, está al servicio de la producción, se habrá cosificado.

De esta forma la relatividad utilitaria está contaminando conceptos como el de libertad y humanidad.

Sólo cuando la razón subjetiva y objetiva se unifiquen podrá superarse esta crisis a la que hoy se ve sometida la razón «la consecución de una situación social en la que uno se convierte en medio para otro es al mismo tiempo la consumación de concepto de razón que, en la descomposición en verdad objetiva y pensamiento formal, amenaza ahora con extraviarse» ${ }^{11}$.

Horkheimer en su artículo «Razón y autoconservación» hace una revisión de algunos conceptos como el de razón, pues «la nueva generación ya no deposita mucha confianza en ellos, y sus sospechas son corroboradas por el fascismo».

Parafraseando a Kant nos dice que el sentido de la historia era llevarnos al

8. Horkheimer, M., Sociológica, Taurus, Madrid 1974, 272.

9. HORKHeIMER, M., Sociológica, 275.

10. HoRKHeIMER, M., Sociológica, 277.

11. Horkheimer, M., Sociológica, 283. 
triunfo de la razón. A ella estaban ligados los conceptos de libertad, justicia y verdad.

Sin embargo, con el escepticismo, la racionalidad se reduce a lo existente, no queda lugar para la utopía.

«Hoy en día la depuración escéptica no deja gran cosa del concepto de razón. Ėste ha sido socavado. La razón al destruir a los fetiches conceptuales, anula finalmente el concepto de sí misma» ${ }^{12}$. De esta forma la razón es algo carente de sentido, sus categorías como, espíritu, voluntad, causa final... han desaparecido.

De todos modos, esta razón no ha sido eliminada completamente, simplemente ha sido reducida a su significación instrumental de manera más radical que nunca; ella se ha convertido en instrumento de la guerra y de los negocios, adecúa los medios al fin y el pensamiento a la economía del trabajo, ella piensa siempre en los beneficios.

La razón fundamenta la subordinación del individuo al todo. La categoría que priva es la de beneficio. Esta razón está al servicio de la autoconservación individual. "La razón se halla bastante lejos de salirse de la esfera del auto interés... Lo que hace es más bien inventar procedimientos para servir con mayor complacencia a cualquier objetivo de la mónada» ${ }^{13}$. Es de tener en cuenta que el deterioro del concepto de razón va parejo con el de individuo. «La categoría del individuo, a la que a pesar de todas las tensiones se hallaba ligada la idea de autonomía, no ha podido resistir ante las presiones de la gran industria... La desintegración del individuo y de la razón son una y la misma cosa» ${ }^{14}$.

Al no ser el individuo dueño de sí mismo, las acciones que éste realice carecerán de sentido para él. «Bajo el imperio del monopolio, el individuo sólo tiene posibilidades a corto plazo». El individuo es un elemento más y pierde importancia en sí mismo, la adaptación suple a la responsabilidad, individuo es igual a disponibilidad. De esta forma desaparece el futuro para el individuo, éste es producto de la cosificación y la unidimensionalidad se impone. "Los seres humanos tienen que repetir los slogans de la radio, cine y revistas para ser en general «soportables»... El individuo ya no tiene que mirar al futuro, debería estar simplemente dispuesto a someterse» ${ }^{15}$. El individuo se encuentra controlado por la producción. Esta unidimensionalidad se da en el campo de la educación, en el familiar y en el del sexo. La violencia practicada por el fascismo, nos dice Horkheimer, parece escarnecer cualquier tipo de razón.

12. HoRKHeIMER, M., Teoría crítica, Barral, Barcelona 1973, 143.

13. HorkHeiMer, M., Teoría crítica, 149.

14. Horkheimer, M., Teoría crítica, 158.

15. Horkheimer, M., Teoría crítica, 161. 
Frente a esta situación el individuo no reacciona con un carácter utópico, como lo hará en Marcuse. "La idea de la transformación es corroída por la conciencia de la desgracia universal... La muerte era el límite mismo del individuo constituido por la autoconservación» ${ }^{16}$.

La razón, en el orden fascista, se revela a sí misma como sinrazón.

Horkheimer termina diciéndonos que lo que aún le queda a la razón es su autoconservación, la razón no se agota en la via autoalienada.

Siguiendo el modelo de la crítica negativa, Marcuse tomó también como punto de partida el fracaso de la revolución proletaria, de ahí que proclame su no identidad con el orden establecido, volviéndose sobre el individuo aislado. Esta vuelta a la particularidad sirve para analizar la afinidad existente entre crítica negativa, psicoanálisis y teoría existencialista.

Marcuse entra en contacto con Freud hacia finales de la década de los treinta. Pero antes de lanzarse al psicoanálisis, influenciado por Heidegger, intenta proyectarse desde el existencialismo. Marcuse elogia a Heidegger por su contribución a los estudios sobre Hegel ${ }^{17}$. También desde esta perspectiva existencialista pretende acercarse a la obra de Sartre. Marcuse recurre al psicoanálisis para, a partir de Freud, buscar la forma de salvar al individuo. Los esfuerzos del psicoanálisis van a encontrar su apoyo en la filosofía liberal cuyo eje giraba en torno a las nociones de autonomía y libertad individual. Sin embargo, ese intento que tiene el psicoanálisis por reforzar el «yo», pone de manifiesto que el individuo acaba sometido al sistema del dominio que él mismo ha construido. El problema planteado por Marcuse es que lo primero que se debe hacer es que el individuo sea posible. En «Cultura y Sociedad» Marcuse pone de manifiesto la contradicción existente entre los valores culturales y los mecanismos de una economía irracional. Este proceder irracional amenaza con anular al individuo; la razón cede ante la voluntad irracional.

Para la figura burguesa, la libertad queda reducida a la vida íntima, privada; de esta forma la libertad fundada en la libertad de la razón ha sido encerrada en la pura interioridad sin que puede conexionar con la praxis social.

Pero donde quiere poner el acento Marcuse, es en que esta vida íntima es también manipulada por la propaganda al servicio de la producción. En el capítulo «Noción de individuo» de "La sociedad», Adorno pretende analizar el concepto de individuo en función del de naturaleza y sociedad. En una primera aproximación a este concepto nos dice: «El individuo designa algo concreto, cerrado y subsistente por sí mismo» ${ }^{18}$. Es, pues, una individualidad carac-

16. Horkheimer, M., Teoría crítica, 170.

17. Marcuse, H., Ontología de Hegel, Mtz. Roca, Barcelona 1969,8.

18. Adorno, TH.W., La sociedad, Proteo Editorial, 44. 
terizada por propiedades particulares que sólo a él le son pertinentes. En primer término, pues, y sin hacer referencia a la persona humana, aparece el «individuum» que es la producción latina del "atomon» materialista de Demócrito. Con la concepción leibniana, el individuo al igual que «mónada», - indiviso y sin necesidad de otro - , goza de plena autonomía, la sociedad no será otra cosa que la suma de singularidades. Esta corriente será seguida por el liberalismo. Pero la labor que la sociedad se impone a partir de estos momentos es mostrar cómo el individuo está socialmente mediado. De esta forma el tema central de la sociología serán las relaciones entre el individuo y la sociedad. A partir de este momento comienza un proceso que va del concepto de individuo autónomo a conceptos como el de convivencia, participación, comunicación. El individuo, antes de serlo, es persona. Estas relaciones mediante las cuales el individuo se determina a sí mismo, no son algo extrínseco. «Quien quiera prescindir de ese carácter funcional de la persona para buscar en cada uno su significado singular y absoluto, no llegará al individuo puro, en su singularidad inefable, sino a un punto de referencia altamente abstracto, que a su vez adquirirá significado respecto del contexto social considerado como principio abstracto de la unidad de la sociedad» ${ }^{19}$.

Adorno a su vez establece una relación. Las relaciones individuosociedad han de estar en conexión a su vez con las de la naturaleza. De la interación de estas tres variables tenemos el acaecer histórico. Pues en tanto es necesaria esta interación en cuanto es natural al hombre el realizarse en comunidad. Éste sería el caso de Aristóteles para quien la polis aparece como condición para ser hombre.

Un punto de vista totalmente contrario encuentra Adorno en la concepción positivista, en donde el individuo quedará subordinado a la sociedad. Por su parte Adorno destaca al individuo como algo dado en la naturaleza. Pero esta individualidad no ha de ser entendida como algo abstracto sino como ser que puede determinarse a sí mismo. En esta conciencia, con proyección a los otros es donde alcanza su plena realización, pues el individuo sólo se realiza plenamente cuando surge en relación de una autoconciencia con otros. Los dos conceptos: individuo y sociedad son, pues, recíprocos.

La mutua interacción de ambos justifica el papel del individuo en la sociedad. «La comprensión de la acción recíproca que individuo y sociedad ejercen, uno sobre otro, tiene una consecuencia fundamental evidenciada por la sociología positiva, en la idea de que el hombre como individuo alcanza su existencia propia en una sociedad justa y humana» ${ }^{20}$. Sin embargo esta ar-

19. Adorno, Th.W., La sociedad, 51.

20. Adorno, Th.W., La sociedad, 57. 
monía se ve rota en las sociedades desarrolladas. El individuo se ve obligado en esta sociedad a perseguir sus intereses al margen de la colectividad. "La sociedad que llevó al desarrollo del individuo, se desarrolla ahora a sí misma alejando de sí al individuo y destronándolo; pero el individuo desconoce ese mundo, del cual él sin embargo depende en lo interno, hasta creerlo todo suyo» ${ }^{21}$.

En este mismo sentido Horkheimer en "Función social de la filosofía», nos dice que los hombres, a pesar del avance de la ciencia, se empobrecen material, espiritual y emocionalmente. «El racionalismo individual puede ir acompañado de un completo irracionalismo general. Los actos individuales que en la vida diaria pasan con toda justicia por razonables y útiles, pueden resultar perjudiciales y hasta destructivos para la sociedad» ${ }^{22}$.

La trayectoria a seguir por la Escuela de Francfort va a ser la de salvar al individuo desde la razón, con ésta se hará posible la unión de individuo y sociedad.

Así Marcuse en «Filosofía y teoría crítica» de "Cultura y sociedad», nos dice: «La razón, que en la nueva filosofía se convierte en el ser auténtico tiene que producirse a sí mismo y crear su propia realidad siempre de nuevo, con un material existente... Lo que la razón debe hacer es nada más y nada menos que la constitución del mundo para el yo. Debe crear la generalidad en la que ha de encontrarse el sujeto racional con otros sujetos racionales») ${ }^{23}$.

En la época burguesa, dice Marcuse, la realidad de la razón se convirtió en la tarea que el individuo libre debía realizar. El sujeto era el depositario de la razón: la racionalidad de la objetividad debía partir de él.

Por su parte, para Horkheimer, en "Ascenso y ocaso del individuo», el individuo concebía la razón como instrumento del yo. El individualismo adquiere su máximo desarrollo con el liberalismo burgués, pero el individuo pronto se ve subordinado a sus intereses económicos. Así en el siglo XIX, nos dice Horkheimer, el peso principal recaía más en el planteamiento, organización y centralización del sistema, que en el destino del individuo. La racionalidad pertenece al dominio, no a la razón, la razón se hace, pues, irracional. Se piensa en la producción y para la producción. De esta forma el individuo ya no tiene forma personal. Se ve bombardeado desde todas las posiciones por las distintas coacciones sociales.

Creemos de interés mencionar la orientación dada por Horkheimer al concepto de psicología en su conferencia «Historia y psicología», recogida en

21. Adorno, Th.W., La sociedad, 58.

22. HorkHeimer, M., Teoría crítica, 278.

23. Marcuse, H., Cultura y sociedad, 82. 
la teoría crítica. Horkheimer toma como punto de partida no la concepción de la historia propia de la filosofía actual sino de una filosofía de la historia, la de Hegel. Sin embargo, cuando el sistema hegeliano cede ante la concepción liberal, con ello, sufre también un cambio el significado que la psicología tiene para el conocimiento de la historia.

Aunque para la llustración y para Hegel el motor de la historia sean los intereses de los individuos, sin embargo, para Hegel, esto es algo sin importancia frente a la ldea que todo lo rige, y el actuar de ésta no es deducible ni de la psique, ni del individuo, ni de la masa. Pero esta Idea no es el inconsciente de la psicología moderna, sino aquel «Telos» inmanente de la historia. Por el contrario para el liberalismo la historia es, en su esencia psicológica, «los individuos con sus eternos instintos sólidamente arraigados en su naturaleza, ya no son sólo los factores inmediatos de la historia, sino también las instancias últimas para la teoría del acontecer propio de la realidad social» ${ }^{24}$.

Para la teoría marxista la dinámica histórica no puede ser explicada desde el individuo sino que los hombres están sujetos a formaciones históricas que tienen su propia dinámica, pero con esto no afirma una teoría psicológica de la historia. Las formas de producción condicionan la marcha de la historia. La concepción económica de la historia se manifiesta como antagónica a la filosofía de Hegel, pues según ellos nada es fundamento de la historia, nada puede ser interpretado como poder unitario, como razón determinante. La historia estará configurada a partir del progreso material. Pero en ningún modo reduce la función propia del individuo.

Horkheimer intentaba hacer una comparación con la teoría liberal donde la psicología condicionaba a la historia, por el contrario «si la historia se articula según los diversos modos en los que se consuma el proceso de la vida de la sociedad humana, no son las categorías psicológicas sino las económicas las fundamentales para el conocimiento histórico. De ciencia fundamental la psicología pasa a ser ciencia auxiliar, por cierto indispensable para la historia» ${ }^{25}$.

Podemos concluir poniendo de manifiesto la interconexión entre individuo, naturaleza y sociedad. Las relaciones de los grupos sociales entre sí se originan en las cambiantes constelaciones que median entre la sociedad y la naturaleza, convirtiéndose en determinantes respecto a la condición de los individuos lo cual repercute a su vez sobre la estructura social ${ }^{26}$.

\section{Modesto SANTOS LÓPEZ}

Instituto Zorrilla.- Valladolid

24. HorkHeimer, M., Teoría crítica, 27.

25. HorkHeimer, M., Teoría crítica, 30.

26. Horkheimer, M., Teoría crítica, 51. 